EGG-SSRE---10.102

TI92 017832

\title{
Current Nuclear Industry Practices With Regard To The Integration Of Surveillances
}

Mike Stewart

Curtis Smith

April 1992

EG\&G Idaho, Inc.

Idaho Falls, Idaho 83415

Prepared for the

U.S. Nuclear Regulatory Commission

Division of System Research

Office of Nuclear Regulatory Research

Washington, D.C. 20555

Under DOE Idaho Field Office

Cuntract DE-AC07-761001570

FIN NO. L1831 


\begin{abstract}
Commercial nuclear industry practices regarding the integration of technical specification (TS) surveillance and maintenance activities are identified in this report. A questionnaire was developed and used to obtain current industry practices from NRC Regional personnel and INEL engineers with utility experience. Some of these practices indicate that the scheduling of TS surveillance and maintenance items could be more effectively coordinated. Also, most utilities do not formally consider risk implications when they are scheduling maintenance. Methodologies and approaches for proposing and evaluating changes to improve the integration of TS surveillance and maintenance activities have been identified for planned future work.
\end{abstract}




\section{CONTENTS}

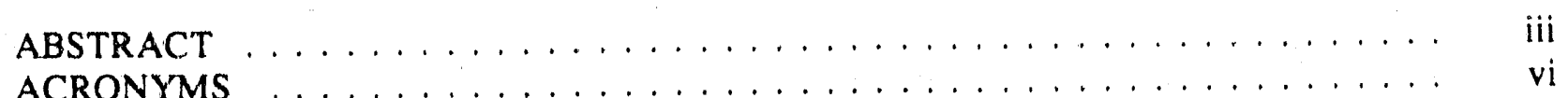

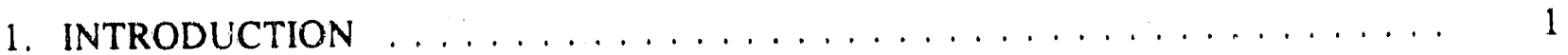

2. APPROACH AND RATIONAL $\ldots \ldots \ldots \ldots \ldots$

3. $\operatorname{TEST}$ AND MAINTENANCE SCHEDULES $\ldots \ldots \ldots \ldots$

4. RISK IMPACT OF SURVEILLANCE $\ldots \ldots \ldots \ldots \ldots \ldots$

5. FEEDBACK $\ldots \ldots \ldots \ldots \ldots \ldots \ldots \ldots$

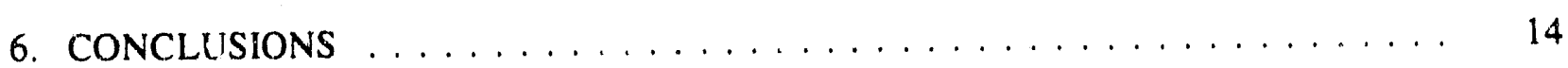

7. METHODOLOGY FOR ASSESSING IMPACT OF INTEGRATING
SURVEILLANCE AND MAINTENANCE $\ldots \ldots \ldots \ldots \ldots \ldots \ldots \ldots$

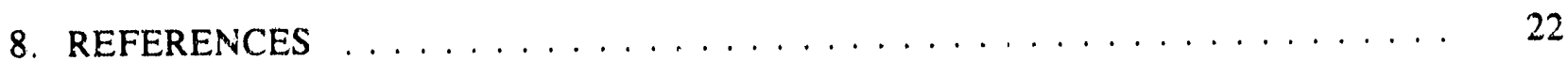

APPENDIX A: Surnmary of Region I NRC Survey $\ldots \ldots \ldots \ldots \ldots \ldots \ldots$

APPENDIX B: Summary of Region III NRC Survey $\ldots \ldots \ldots \ldots \ldots \ldots$

APPENDIX C: Summary of Former Nuclear Utility Engineer Survey . . . . . . . . . C-1 


\section{ACRONYMS}

$\begin{array}{ll}\text { AOT } & \text { allowed outage time } \\ \text { ASME } & \text { American Society of Mechanical Engineers } \\ \text { BWR } & \text { boiling water reactor } \\ \text { ECCS } & \text { emergency core cooling system } \\ \text { I\&C } & \text { instrumentation and control } \\ \text { INEL } & \text { Idaho National Engineering Laboratory } \\ \text { LCO } & \text { limiting condition for operation } \\ \text { NPRDS } & \text { Nuclear Plant Reliability Data System } \\ \text { NRC } & \text { Nuclear Regulatory Commission } \\ \text { PRA } & \text { probabilistic risk assessment } \\ \text { PWR } & \text { pressurized water reactor } \\ \text { RCM } & \text { reliability centered maintenance } \\ \text { RHR } & \text { residual heat removal } \\ \text { STI } & \text { surveillance test interval } \\ \text { TS } & \text { Technical Specifications }\end{array}$




\section{Current Nuclear Industry Practices With Regard To The Integration Of Surveillances}

\section{INTRODUCTION}

The purpose of this report is to identify the practices currently used by the nuclear power industry to integrate technical specification (TS) surveillance and maintenance activities. The term "integrate" signifies the combination of TS surveillance and maintenance activities with other plant knowledge bases to optimize resource usage and realize a net risk reduction. Some examples are:

- Avoiding surveillance testing during operation in plant configurations in which test errors could initiate transients.

- Conducting tests when they are particularly important from a risk perspective (for example, to assure alternative success paths when a train of an important safety system is inoperable).

- Allowing flexibility such that test intervals, as described above, can be optimized. This might also reduce the number of tests, and thereby reduce the opportunity for human errors.

- Providing feedback regarding performance data to ensure that new problems are recognized as they arise, their root causes are uncovered, and the maintenance and surveillance programs are adjusted as appropriate.

Because of these potential benefits, the U.S. Nuclear Regulatory Commission (NRC) is interested in determining the existing industry practices with respect to integration. Also, the NRC has investigated developing methods or approaches to analyze and improve the integration of surveillance testing and maintenance. For example, the Commissioners encouraged the staff to move forward with the risk based TS program. Additionally, the NRC has realized that this research would help to develop a regulatory position concerning maintenance outage planning.

Also, the nuclear industry is becoming increasingly interested in these testing and maintenance issues. One utility performed a probabilistic risk assessment (PRA) for all maintenance that had occurred in the previous year and compared that to the expected core damage if only corrective maintenance were performed. They found that the core damage risk doubled due to the excessive maintenance during limiting conditions for operation (LCOs). ${ }^{l}$ This interest has resulted in directing the Idaho National Engineering Laboratory (INEL) to identify the existing industry practices with regard to integration, and to propose approaches and methods to analyze and improve the current practices. 
The total scope of work for this project has been split into three tasks. Task 1 is to identify existing industry practices for integration and is the specific topic of this report. Task 2 is to gather, develop, and demonstrate approaches and methodologies for evaluating and improving integration. Task 3 is a pilot project, with a utility, to validate the methods and approaches prepared in Task 2.

To identify industry practices, a questionnaire was developed and given to NRC Regional personnel and to INEL engineers who had previous utility experience. Meetings were conducted separately with NRC personnel from Regions I and III where the questionnaire was discussed with resident inspectors and regional headquarters technical experts. Since the questionnaires were conducted in a group, the answers represent a composite opinion. In order to address any possible regulatory bias and to supplement this information, the questionnaire was given to INEL engineers who had utility experience. These questionnaires were given individually and the answers were then combined into a composite response. The resultant information from the questionnaire is organized and analyzed in the following sections, starting with the methodology and rational used in the development and application of the questionnaire.

In the first of the following sections (Approach and Rationci), the approach for organizing the questionraire and the rational for how it was applied is described. The approach that was used resulted in the identification of three steps that identify a general program to integrate TS surveillance and maintenance activities. These three steps (Test Schedules, Risk Impact of Surveillance, and Feedback) are used as headings for the remaining sections of the body of this report, where the existing industry practices are identified.

The final two sections of this report contain the conclusions and describe the general approach that will be taken for the next task (Task 2) of this project. 


\section{APPROACH AND RATIONAL}

In this section, the discussion covers the approach used for the organization of the questionnaire and the rational used for its application.

\subsection{Approach}

The questionnaire needed to be designed to collect the kind of information that would identify the existing industry practices on the integration of TS surveillance with maintenance activities. To accomplish this, a program was defined that identified the elements needed to achieve integration.

Three basic elements can be defined for any general program or process. The first element is the activity of the program. The second element is the means to measure the success of the process. The third element is a means of feedback from the measured results to the program activity so the program can be changed effectively. The relative success of any program is dependent upon how well each of these steps is implemented. The three basic elements are shown schematically in Figure 1.

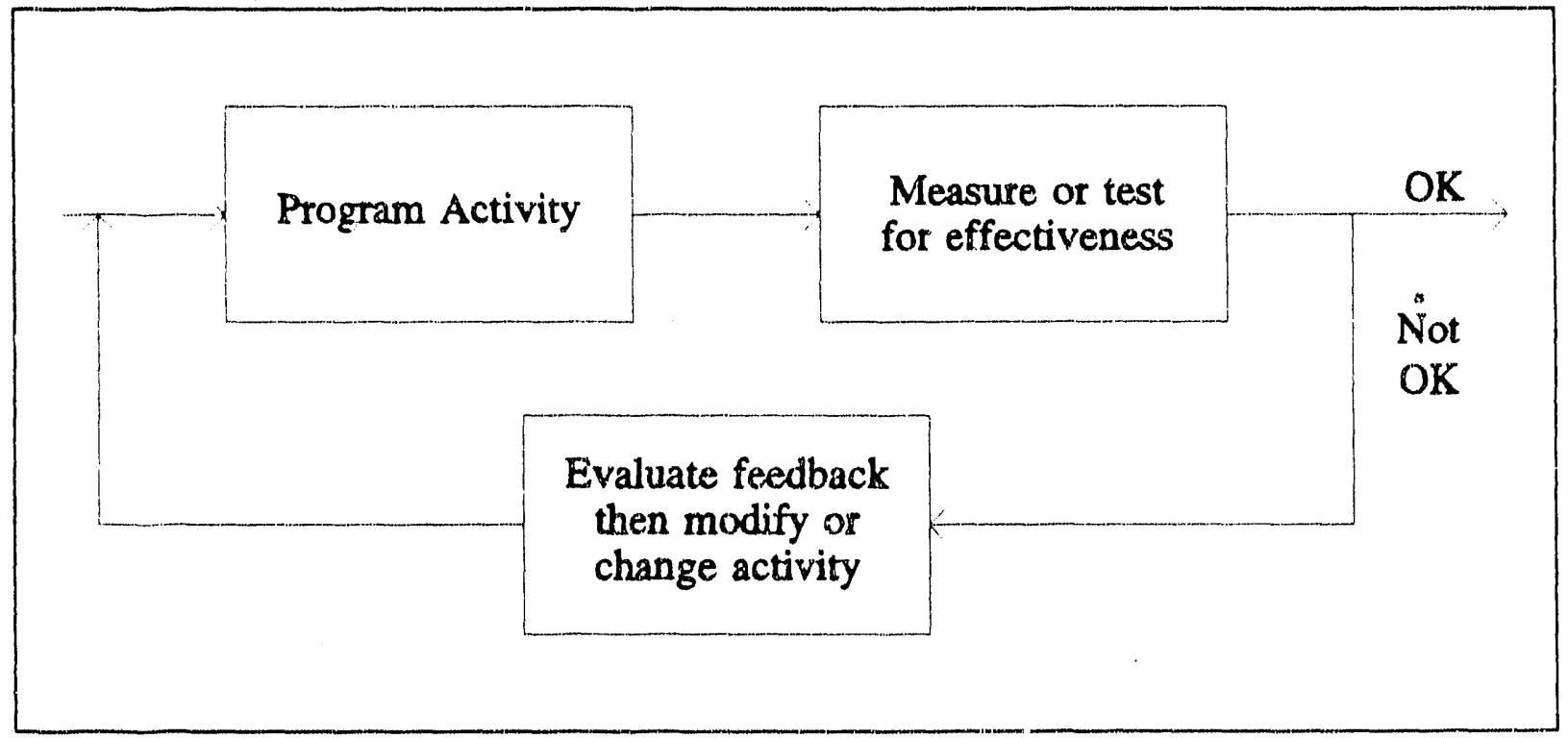

Figure 1. Generic process flow diagram.

Starting with the three basic elements, a program specifically to integrate surveillance and maintenance testing was defined. The first program element addresses test and maintenance scheduling. The second element addresses measuring the risk impact of surveillance and maintenance activities. The third element addresses the process feedback. The specific program elements are shown schematically in Figure 2. 


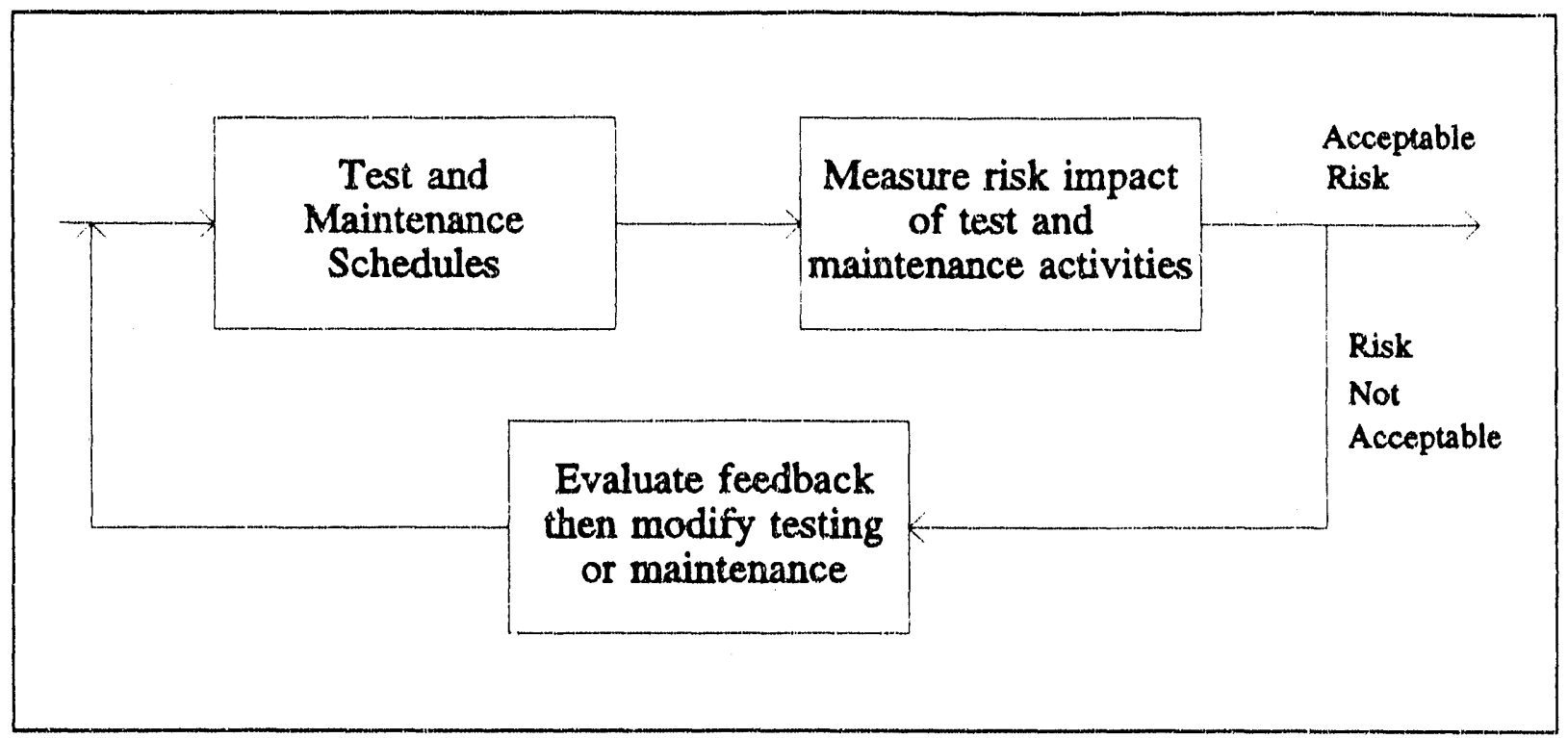

Figure 2. Surveillance and maintenance integration process flow diagrarn.

The intent of the project is to understand what the current industry practices are with regard to the elements in Figure 2. However, the programs that are currently set up in the industry are not necessarily set up to optimize the integration of TS surveillance with maintenance activities. Likewise, many plants may not measure the effectiveness of their testing programs specifically with risk measures.

With this in mind, a questionnaire was devised that contained a series of questions and discussion topics. These questions or topics were selected to cover all the areas needed to obtain the present state of industry practices regarding the integration of TS surveillance with maintenance activities. These questions and topics were then divided into three categories corresponfing to the three elements of the process shown in Figure 2.

\subsection{Rational}

The original project plan was to visit individual plants and obtain information directly from plant personnel using the questionnaire. It was decided, however, that collecting data this way would be too time consuming and ineff,cient. Instead, a combination of discussions with NRC Regions I and III personnel and INEL cognizant personnel was performed.

By utilizing NRC personnel (especially resident inspectors) it was felt that a knowledgeable and objective viewpoint could be more efficiently achieved. The resident inspectors have knowledge of the plant they are presently stationed at, while many have had experience at more than one plant. The viewpoints of the resident inspectors, when combined with the knowledge provided by NRC 
Regional personnel with responsibilities to oversee maintenance and operations activities, gave a considerable amount of usable information. Because of the group discussion and the multiple plant experience that was represented, a broad base of plant experience was obtained.

The information obtained from INEL engineers, who were former utility personnel, was used to supplement the information gained from the NRC regional offices. This information was also used to validate the information gained from the NRC regional offices and to account for any possible bias that might result from hearing a regulatory viewpoint without hearing a utility viewpoint. By obtaining the information in this way, plants from every region except Region $V$ were represented, including older and newer plants, large and small utilities, and plants from every nuclear steam supply system vendor.

The composite answers obtained from NRC Regions I and III and the INEL engineers are contained in Appendices $\mathrm{A}, \mathrm{B}$, and $\mathrm{C}$ respectively. The existing industry practices derived from these appendices are established in the next three sections. 


\section{TEST AND MAINTENANCE SCHEDULES}

Test and maintenance schedules represent the process that implements TS surveillance and maintenance activities. As discussed earlier, this is the first element in the program that was defined for the integration of TS surveillance and maintenance activities.

The following sections correspond directly to the questions or topics contained in the questionnaire. In these sections, the existing industry practices with regard to test schedules are identified. The practices are derived from the composite answers on the questionnaires given to NRC and INEL personnel. The practices are identified and organized in the same order as the questions that were grouped under this element heading in the questionnaire. The practices identified are a composite and do not necessarily apply to all plants.

Although the questions have been grouped according to the three elements of the process for the integration of TS surveillance and maintenance activities, much of the information obtained and listed under one element can apply to the other elements.

\subsection{Discuss whether it is possible to perform maintenance without declaring the associated train inoperable.}

If maintenance was of such a nature that it could be done without impairing a component's or a system's ability to carry out its designated safety function, the train would not be declared inoperable. Examples of some types of maintenance that might fall under this category are the adding of oil to a pump or testing a system (if it can re-align on an automatic signal). The majority of the maintenance, however, required the train to be declared inoperable. This is a consistent practice throughout the industry.

However, the interpretation of when to declare a train inoperable varies somewhat throughout the industry. There is also some variation as to what constitutes the disabling of an automatic starting feature.

3.2 If a safety-system train is declared to be inoperable, what testing or assurance activities are performed before the train is declared operable? How do these postmaintenance activities differ from surveillance testing?

Surveillance tests are required to be run at specified periods by a plant's TSs. The purpose of the test is to ensure that key components are operable and capable of carrying out their designated functions. Post-maintenance testing is done to ensure the maintenance activity performed was successful. The post-maintenance testing will only encompass the equipment associated with the maintenance activity. Therefore, the post-maintenance testing scope is defined by the scope of the maintenance. There is no periodic post-maintenance testing (except for those associated with prevent $^{\circ}$ e maintenance activities) and no regulatory requirements to perform it exist, but the testing is performed as dictated by good maintenance practices. 
Often, post-maintenance testing is derived, at least in part, from surveillance test requirements. Post-maintenance testing can be the same, less than, or more than surveillance testing. However, generally the post-maintenance testing requires tests that represents only a portion of the surveillance testing; thus, credit can not be taken for completing a surveillance test. Postmaintenance testing does not always recognize the worst case conditions.

It is also common practice to perform a post-maintenance operation, such as stroking a valve, prior to performing the associated surveillance test. In such cases, the component will pass a surveillance test that it might not otherwise have passed. Therefore, trending of failed components or tests varies greatly in the industry. For example, at some plants, if a repair does not pass a postmaintenance test, the maintenance activity is continued until it does pass, and the intermediate test failures are not reportable to the Nuclear Plant Reliability Data System (NPRDS).

\subsection{Discuss how surveillance and maintenance schedules are coordinated. Is survillance routinely performed following maintenance?}

The consensus seems to be that surveillance and maintenance schedules are not well coordinated. This seems to be more the case for situations involving unplanned maintenance (rather than for planned maintenance) and for plants with less operating experienco.

Depending on the scope of the post-maintenance testing needed and the time remaining until the end of the surveillance interval, the plant may decide to plan post-maintenance testing that satisfies a surveillance requirement.

\subsection{Are surveillances performed only at the specified intervals, or are they performed more often (i.e., following maintenance or inspection activities)?}

In general, surveiliances are performed more often than required by the surveillance test interval. Poor physical condition of the plant's components contributes to a requirement for increased tests. Sornetimes testing is performed to match the shift schedule. For example, a test scheduled for every 12 hours may be performed every eight hours to insure that the test will not be overlooked and that all personnel will remain familiar with the test. Also, most plants are on a rolling maintenance schedule.

In many cases, plants will enter an allowed outage time (AOT) to perform routine maintenance. By doing this, the plant can spread maintenance activities out rather than allowing them to collect to be done during an outage. This allows the plant to do more of the maintenance using their own personnel. Allowing maintenance activities to collect until outage creates a peak load of work requiring the utility to rely on contractors to supplement their in-house staff. The contractors are, in general, less familiar with the plant and equipment than are the in-house staff. However, the practice of using AOTs to perform routine maintenance activities adds to the unavailability of equipment. 


\subsection{Are there any mechanisms in place to automatically schedule surveillances after maintenance activities have bein performed?}

If a surveillance is run and a piece of equipment fails the test, and if the equipment is judged to be inoperable, a maintenance activity will be initiated to fix it. Once the equipment is believed to be fixed, the surveillance is run to demonstrate operability. If, however, a preventive maintenance activity is being run or if corrective maintenance is being performed on a piece of equipment that has not been deemed as inoperable, TSs do not specifically require that a surveillance be run. Most likely a post-maintenance testing activity that may be derived in part from a surveillance test will be performed. In any event, this is usually scheduled manually by an individual that is assigned to be the expert or coordinator for these activities at the plant. Only in the case where maintenance was being performed as the result of a failed surveillance could it be said that a surveillance is automatically scheduled. In such a case it is not so much a situation of scheduling a new surveillance activity as it is repeating the failed surveillance until the repaired equipment passes the test.

3.6 Have plants discussed the potential usefulness of more flexible surveillance test intervals (STI)? Have any attempts been made to optimize STIs using PRA or other risk/reliability tools? (Optimizing STls refers to finding the surveillance interval with the smallest risk associated with it.)

There have been some cases where plants have changed or attempted to change the STIs for specific equipment, but these cases are rare. Whenever such attempts have been made it was to lengthen the STIs, never to shorten them. There are no known programs where a plant is looking at a total picture of the various STIs and how they might be interrelated and the various tradeoffs that might exist. In some cases, the TSs will be used to drive testing requirements in a way that might increase risk. For example, if one of two redundant trains is found to be inoperable, the TSs do not require testing the redundant train for operability until the AOT is nearly over. If there is a common mode failure mechanism causing the failure, then plant risk is increased by delayed testing of the redundant train. Situations do exist where TSs during shutdown allowed one train of emergency core cooling system (ECCS) to be inoperable at the same time the normal emergency power source for the operable ECCS train was unavailable.

Programs exist at some plants for doing PRAs, reliability, reliability centered maintenance ( $\mathrm{RCM})$, and predictive maintenance procedures, but few of the PRAs have been completed and the other programs are mostly in the beginning stages. In many cases, when projects or programs like these are completed at a plant, they are then applied in varying degrees (including not at all). It was noted that single unit utilities are less likely to participate in using or employing these techniques. The general conclusion is that most of these tools have not been employed to any great extent. But, the reason for this lack of use may be because they are so new as to be not fully developed or not enough experience has been gained to know how to best employ them. 


\section{RISK IMPACT OF SURVEILLANCE}

This section addresses the second element in the process that was defined for the integration of TS surveillance and maintenance activities. This element is the measurement of success of the program activity as compared against a specified criteria. The criteria chosen for thi: process is "risk impact," which, is probably not the general criteria used at most pla"ts. For the purposes of this project, however, there is a need to know what the existing practices are with regard to a measure of risk impact.

In this section, the existing industry practices with regard to the measurement of risk iiput are identified. The practices are derived from the composite answers on the questionnaires given to NRC and INEL personnel. The practices identified are a composite and do not necessarily apply to all plants.

Although the dues: :ons have been grouped according to the thre? elements of the process for the integration of TS surveillance and raintenance activities, much of the information obtained and listed under one element can apply to the other elements.

\subsection{To what extent do plants tend to perform surveillance and maintenance in a formal way (written procedures, dedicated groups, formal training) and to what extent do they approach it informally (few or no procedures, assigned as collateral duty, training by word of mouth, etc.l?}

Surveillance activities are performed in a very formal manner. Maincenance activities are sometimes performed in a less formal manner, particularly at older plants that tend to rely less on detailed work instructions and rnore on the experience of longtime employees. Major maintenance activities are usually controlled in a fairly formal manner, and some plants have considered possible risk tradeoffs involved with major non-routine maintenance items. In general, the risk tradeoffs are not routinely addressed and when they are it is infornally.

Training for surveillance activities is formal, and generally, is also formal for maintenance. Surveillance and maintenance astivities are performed by groups specifically set up to perform these activities as a primary duty. Most plants have an organization or individual who is specifically assigned to schedule and track surveillances. Also, maintenance is usually scheduled but cends to be less coordinated between different groups and some of the scheduling may be a collateral duty. For example, some maintenance activities may be performed by an instrumentation and controls (I\&C) group on a piece of equipment, but this may not be coordinated with work that is being performed by a mechanical maintenance group on the same piece of equipment. The reason for this is that at many sites these groups may not report to the same manager or a master schedule that includes all maintenance activities is not used. 
4.2. In approximately what fraction of preventive maintenance activities could maintenance or test errors potentially disable the component or its associated train? In these instances approximately how much time could elapse before the associated surveillance was performed?

A large percentage of preventive maintenance activities have the potential to disable a component or its associated train. Estimates ranged from 10-90\%. However, in most cases it was felt that the post-maintenance lesting would catch the majority of these items. As a result, very few errors would get through. For example, one plant was cited as having only three or four rewcrks out of about 5000 maintenance activities. It should be noted that the definition if rework varies greatly from one plant to another.

4.3 Discuss the extent to which plants include risk considerations in deciding what maintenance to do during power operations. For maintenance that is undertaken during shutdowr conditions, do plants routinely prepare work packages to have on hand in the event of any unplanned outages?

The operations department usually decides what maintenance will be done, and their decisions are based more on technical specification requirements than on risk considerations. In general, the idea prevails that if the plant is operating within TSs (AOTs, STIs, atc.), the plant is operating safely, and therefore. other considerations are minimal. For example, in the past most plants did not consider the risk of decay heat removal loss. Examples of where plants do consider risk are: 1) pressurized water reactor's (PWR) mid loop loss of residual heat removal (RHD, "2) bciling water reactor's (BWR) loss of shutdown cooling, and 3) loss-of-electrical-grid risk.

With the exception of a few isolated cases, risk was not a consideration in deciding what maintenance to do duting power operations. In those cases where risk studies or PRA groups were consulted, it was on an informal basis. Almost all plants have work packages ready to go in the event of an unplanned outage.

4.4. When a train of a risk significant safety system is inoperable, do plants test or otherwise assure the availability of the other train or alternative success paths beyond what is required in the technical specifications?

The answer generally given to this question was that plants do not test beyond what is required in the TSs. As stated previously, some plants will not check the redundant train until the disabled train is fixed. Often, problems of a certain type happen so frequently that they become routine. In such cases, and in general, it was felt that good root cause determinat w would eliminate many problems and lead to the identification of others in similar systems. It was also felt that good root cause determinations were generally lacking.

Systems not covered by TSs can be and sometimes are taken out of service for long periods of time. For example, the alternative shutdown system is covered by 10 CFR 50 Appendix A, but not by TSs. Situations were discussed where this shutdown system, even though it had safety significance, was sometimes left out of service for long periods of time. 


\section{FEEDBACK}

This heading represents the third element in the process that was defined for the integration of TS surveillance and maintenance activities. This element provides the means by which the program fieds back to itself such that positive changes can be realized.

In this section the existing industry practices with regard to feedback are identified. The practices are derived from the composite answers on the questionnaires given to NRC and INEL personnel. The practices identified are a composite and do not necessarily apply to all plants.

Although the questions have been grouped according to the three elements of the process for the integration of TS surveillance and maintenance activities, much of the information obtained and listed under one element can apply to the other elements.

5.1 To what extent do utilities track equipment performance and condition and maintenance and test errors? Is this information fed back to engineering for evaluation and problem identification? Is this feedback provided to operations and maintenance to help improve performance?

In general, the impression was that a lot of data is collected but not enough time was being spent on analyzing it. In many cases, some good tools were in place but they were used primarily to perform trouble shooting. With some notable exceptions, there was little tracking and feedback of human errors. Again, it seemed that many of the efforts and programs underway were too new and had not had time to be fully developed or incorporated into the plant's risk analysis methods.

Feedback to offsite engineering was considered to be relatively good when it was requested, but overall, feedback to organizations such as PRA groups and feedback in general was not considered to be gnod. There were some plants that were given as exceptions to this situation, but they were in the minority.

5.2 Discuss whether actual equipment failure rates have been factored into lengthening or shortening STIs? For example, if the plant is shutdown in mid-cycle for maintenance, are important valves tested, even though technical specifications require only testing during refueling? Similarly, are surveillance intervals lengthened for equipment that never fails.

In general, failure rates have not been factored into lengthening or shortening test intervals. One notable exception is that some of the testing on the emergency diesel generators has been modified. Most plants have not completed their PRAs and therefore do not yet have the tools to evaluate risk tradeoffs. Those plants that have completed their PRAs or have RCM programs still have not had the time or the inclination to use thiem for such purposes. 
It is always possible to test more often than the established test interval, but to test less often requires a TS change. In those cases where systems or components are tested more often, it is usually not a result of evaluating failure rates, but is driven by the needs to insure that TS requirements are being met. As previously indicated, most of the test interval changes that have been proposed have been to lengthen them, and even these have been few.

\subsection{To what extent do utilities apply their PRAs to determine risk significant failures or errors in order to prioritize and plan maintenance and testing?}

Again, few plants have a PRA in place. Those that do have not generally used the PRA for this purpose. Some plants have evaluated the use of RCM, but have not used it to do these types of analysis either. And, in some cases, it was noted that many plants had stopped any work they were doing in this area.

There seems to be a perception that the NRC has not given the licensees any incentives to use PRAs to justify TS changes. Therefore, maintenance priorities are driven by the need for power generation within existing TS limits.

\subsection{Discuss examples of plants that have a defined and integrated program to incorporate lessons learned from their PRAs and reliability programs back into their surveillance and maintenarice programs?}

Most plants have a low-key (or non-existent) program to integrate PRA and reliability information back into their surveillance and maintenance activities. Funding and interest for performing work that feeds back PRA and reliability data into other programs is generally low. When these programs do exist, it is usually assigned as a low level collateral duty. The general appraisal was that coordination between groups and areas of responsibility left much to be desired. Some exceptions to these observations were noted, but even in these cases, the prograns tended to be informal. It was also noted that the typical PRA document was really not a hanly reference document nor was it readily available to every maintenance engineer.

5.5 Discuss examples of plants where the groups responsible for surveillances, testing, maintenance, data analysis, trending, and modeling (PRA, reliability) are well coordinated and communicate well? Bad examples?

With some exceptions, these areas at most plants generally did not communicate well when considering all areas of the plant. Some plants did well in some of the areas but not others.

PRA was consistently the area that was listed as least integrated with the other areas. Reasons often cited for this were that plants are not oriented toward this type of work and that it was a fairly new analysis area for many plants. 


\subsection{Discuss organizational structures or divisions of responsibilities that you have observed to help or hinder surveillance and maintenance?}

The following examples were given as things that helped the feedback process:

a. Engineering support working at a level directly supporting the operations department.

b. Dedicated maintenance planning that is driven by risk priorities.

c. Involvement and visibility to operations by engineering and corporate management.

d. Systems engineers who work directly with operations.

e. Work planning that is directly responsible to the maintenance or operations department.

f. Cocrdination between groups to expedite work packages.

g. Multiple engineering and technical groups with clearly defined areas of responsibilities.

h. Radiation protection personnel located on site with 24 hour availability to maintenance.

i. A maintenance engineering staff that is associated directly with maintenance.

j. Industry wide experience is efficiently circulated to departments within the plant.

Things that hindered the feedback process were:

a. Engineering support at only the corporate level.

b. Work planning driven by schedule.

c. Junior level systems engineers with little exposure to operations.

d. Lack of health physics support on the back shift

e. Work planners responsible to offsite organizations.

f. Multiple engineering groups without clearly defined responsibilities.

g. Engineering groups located outside the fenced area. 


\section{CONCLUSIONS}

In this section, conclusions regarding the existing industry practices associated with the integration of TS surveillance and maintenance activities will be stated. This summarizing will be performed under the same headings that were discussed in the three previous sections.

These conclusions represent a culmination of the information contained in the previous sections and are generalized from the questionnaire responses. It should be noted that individual plants may represent exceptions to the stated conclusions.

\subsection{Test and Maintenance Schedules}

1. With the exception of very minor non-invasive procedures (like adding oil to a pump), almost all maintenance requires the declaration of the train as inoperable.

2. The interpretation of when to declare a train inoperable and as to what constitutes the disabling of an automatic starting feature varies somewhat throughout the industry.

3. Post-maintenance testing is often derived from surveillance test requirements but rarely include all the surveillance test requirements for any particular piece of equipment. As such, credit cannot be taken for completing a surveillance test. However, depending on the extent of the maintenance testing required and the time remaining until the next related surveillance test is due, the plant may perform post-maintenance testing that also satisfies surveillance lesting.

4. Sometimes a component is exercised prior to performing the associated surveillance test. In such cases a component may subsequently pass a surveillance test that it might otherwise have failed. Therefore, failure reporting can vary throughout the industry.

5. Surveillance and maintenance (especiaily unplanned) schedules are not well coordinated.

6. Planned surveillances are normally scheduled to meet the TS requirements for the STI. However, if a component is in a poor physical condition, a significant amount of corrective maintenance will be required. As a consequence, a surveillance test may be run more often to verify that the system is operab' :. Also, sometimes increased testing is done to match the shift schedule (i.e., a 12 hour test performed every 8 hours).

7. Sometimes plants enter an AOT to perform corrective and preventive maintenance.

8. Post-mainienance tests are automatically scheduled for planned maintenance activities and are manually scheduled for unplanned maintenance activities. The extent of the post-maintenance tests depend on the scope of the maintenance performed. 
9. Scheduling surveillances to be performed after maintenance is coordinated usually through an individual. There is a learning curve to do this efficiently and, therefore, older plants tend to do a better job than new plants.

10. It is rare for plants to propose and justify a change to the test interval of a TS. When such a change is proposed, it is almost always for an increase in the interval and never a decrease.

11. It is standard practice that a redundant train will not be tested for a failure that caused the first train to be inoperable until the first train is fixed or until the AOT is nearly over.

12. PRAs and similar tools have not seen extensive application because they do not exist at some utilities or because their utilization is seen as a marginal use of plant resources. Single unit utilities seem less likely to participate in the development or employment of these techniques.

\subsection{Risk Impact of Surveillance}

1. Surveillance testing is planned and carried out in a very formal mannel with detailed schedules and written procedures. Maintenance is less formally planned, especially with corrective (unscheduled) maintenance (preplanning is not as thorough as scheduled maintenance). However, major maintenance jobs are generally more formally planned and executed.

2. Risk tradeoffs are not routinely addressed and when they are it is informally.

3. It is common practice at many plants to have I\&C and mechanical maintenance groups reporting to separate management, which results in the two groups performing their maintenance and testing using separate schedules.

4. A large percentage of maintenance activities have the potential to disable a component or its associated train. However, because of post-maintenance testing, most errors will be caught.

5. Adhering strictly to TS requirements is the main (and in most situations the only) risk related concern when performing testing and maintenance during operations. Other than informal discussions, risk considerations are not routinely addressed.

6. It is routine practice to have work packages prepared and in standby in the event there is an unexpected outage.

7. Sometimes systems having safety related aspects (e.g., the alternative shutdown system) are left out of service for long periods of time. Systems like these are covered by 10 CFR 50 Appendix A, but are not covered by TSs.

8. Good root cause determinations are lacking at many plants. 


\subsection{Feedback}

1. In general, there is little tracking and feedback of human errors.

2. Although many plants are collecting a lot of data, the tools to use or analyze it have not been developed or employed to any appreciable extent.

3. Feedback and communication between organizations varied from plant to plant, but was generally considered poor with regard to feedback to PRA groups.

4. From the viewpoint of actual application, PRAs, RCM programs, and similar tools and technologies are not yet in wide-spread use at utilities.

5. A surprising observation was the perception that the NRC has not given licensees any incentive to use PRA (or PRA related tools) to justify TS changes.

6. Most plants have low key or nonexistent programs for incorporating lessons learned from their PRAs or reliability programs into operational decision making.

7. At most utilities, PRA documents and information do not exist in an easy-to-use format to support operational decision making. The documents that do exist are not widely distributed.

8. Keeping the plant operating within the TSs is the main, if not the only, focus at many plants. Feedback mechanisms that are in place at these plants are mainly those that are geared to measuring the success of meeting TSs and promoting high capacity factors. Therefore, few, if any, feedback mechanisms that are based on risk measures exist.

9. Practices that promote feedback are:

a. Engineering that directly supports the operations department, multiple engineering groups that have well defined responsibilities, and senior level system engineers with operations background.

b. Maintenance that has dedicated planning, is driven by risk priorities, and has 24 hour access to onsite radiation protection personnel.

c. Industry wide experience that is efficiently circulated to various groups within the plant and coordination between these groups to expedite work.

10. Practices that inhibit feedback are:

a. Engineering groups that support the operations department only at the corporate level, that have junior level systems engineers with no operations background, that have multiple groups without clearly defined responsibilities, and are located outside the fenced area.

b. Work planning driven by schedule, lack of health physics support on the backshift, and work planners responsible to offsite organizations. 


\section{METHODOLOGY FOR ASSESSING IMPACT OF INTEGRATING SURVEILLANCE AND MAINTENANCE}

Task 2, Methodology for Assessing Impact of Integrating Surveillance and Maintenance, of the Integrated Surveillance project involves four primary steps: 1) obtaining project information, 2) evaluating component unavailabilities, 3 ) analyzing surveillance and maintenance integration effects, and 4) developing testing and maintenance guidelines based on the integration effects. These steps are discussed in detail below.

While the steps below are intended to embody the complete methodology needed to finish Task 2, some alternative methods of analysis may be used to enhance the project which are not specified below.

1. Obtain information relevant to the project.

a. Evaluate technical reports addressing maintenance or surveillance. Also, obtain a completed PRA that has detailed fault trees for the systems which will be investigated (only one or two example systems will be investigated). If the fault trees are not detailed enough for thorough analysis, add additional events or components as appropriate.

b. Develop or obtain maintenance and testing schedules for the components in the fault trees.

c. Obtain applicable data, such as component failure rates, test-caused failure rates, test quality as a function of test interval, etc.

2. Evaluate the basic event unavailabilities (probability of component failing to perform its intended function). The unavailabilities may be quantified using one or more of the methodologies below. For this portion of the project, the method that is deemed to be the most applicable and efficient for the test case will be utilized.

a. Evaluate state-change unavailability through Markov modeling.

b. System unavailability may be calculated using an availability/reliability computer code such as FR.ANTIC.

c. The fault trees may be quantified through computer codes such as IRRAS.

3. Investigate the effects that integrating surveillance testing with maintenance will have on the overall core damage frequency or system unavailability.

a. Modifying test intervals may change overall system unavailability.

b. Test integration with maintenance may reduce system unavailability. 
c. Perform sensitivity analysis to evaluate the magnitude of effects that changing test intervals or integrating testing with maintenance will have on the overall system unavailability.

4. From the technical findings, develop guidelines and criteria for the integration of surveillance testing with maintenance.

a. The guidelines or criteria which turn out to result in marginal risk reduction will be eliminated.

b. If possible, a quantitative ordering of the criteria will be presented. From this list, the most beneficial criteria will be apparent. If a quantitative listing is not possible, a qualitative ordering of the guidelines and criteria will be presented. This ordering will be determined by experience and judgement.

Figure 3 shows a process diagram of the Task 2 steps tisisussed above. As shown in the figure, one of the steps in the procedure is to evaluate $t$ : basic event unavailabilities. A component's unavailability may be broken down into sever., different categories. The total unavailability for a component, given by $\mathrm{Q}_{\text {total }}$, can be calculated by:

$$
\begin{aligned}
\mathrm{Q}_{\text {total }} & =\text { (component failures })+(\text { component outages }) \\
& =\left(\mathrm{q}_{\mathrm{FR}}+\mathrm{q}_{\mathrm{FD}}+\mathrm{q}_{\mathrm{FS}}\right)+\left(\mathrm{q}_{\mathrm{ST}}+\mathrm{q}_{\mathrm{CM}}+\mathrm{q}_{\mathrm{PM}}\right)
\end{aligned}
$$

where the unavailabilities are $\mathrm{q}_{\mathrm{FR}}$ (operating failures), $\mathrm{q}_{\mathrm{FD}}$ (failures to $\cdot \mathrm{art}$ ), $\mathrm{q}_{\mathrm{FS}}$ (standby failures), $q_{S T}$ (surveillance testing), $\mathrm{q}_{C M}$ (corrective maintenance), and $\mathrm{q}_{\mathrm{PM}}$ (preventive/predictive maintenance).

A graphical representation of the unavailability that may occur over a typical time period is shown in Figure 4. The figure illustrates the effects that integrating surveillance testing with maintenance may have on the overall system unavailability.

Increasing or decreasing the STI may change the above unavailability terms. The Task 2 methodology will address the issues that arise due to the modification of the tests or maintenance intervals. For example, a number of the potential effects due to increasing only the STIs are:

1. The term $\mathrm{q}_{\mathrm{FR}}$ should remain constant since it is independent of the test interval.

2. The term $\mathrm{q}_{F D}$ is a function of the demand failure rate and the number of demands. As such, it should be constant and should not be a function of the test interval.

3. The term $q_{F S}$ is a function of the standby failure rate and the length of the test interval. Accordingly, increasing the test interval should increase the unavailability (i.e., the familiar $\lambda t / 2$ term increases since $t$ increases). Even though the standby failure rate $(\lambda)$ should be constant, the stanoby failure rate may increase due to less exercising of the component (e.g., corrosion may build up), while at the same time may decrease due to less wear on the component. 


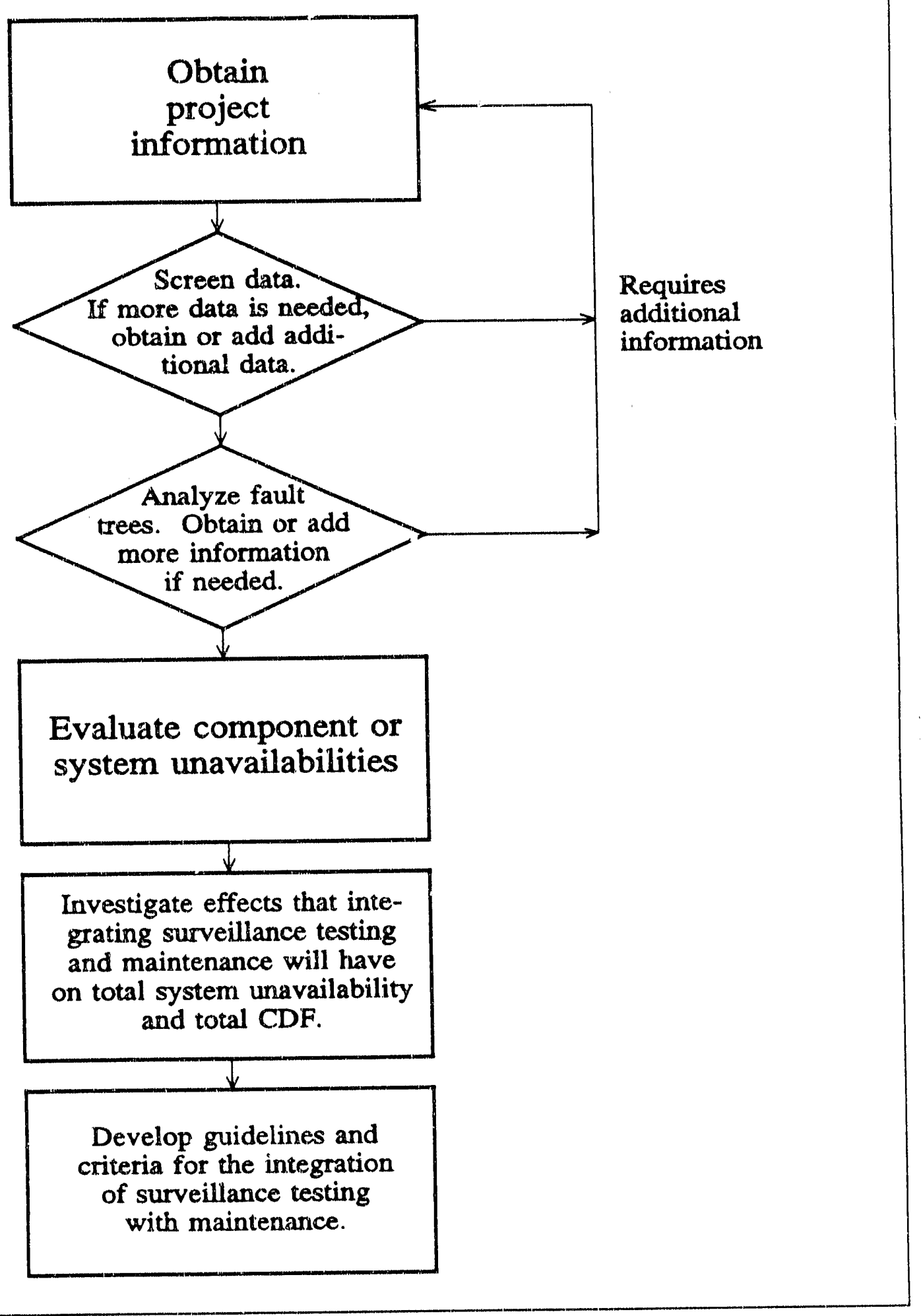

Figure 3. Process Diagram for Task 2 of the Integrated Surveillance Project. 


\section{Testing And Maintenance Not Integrated}

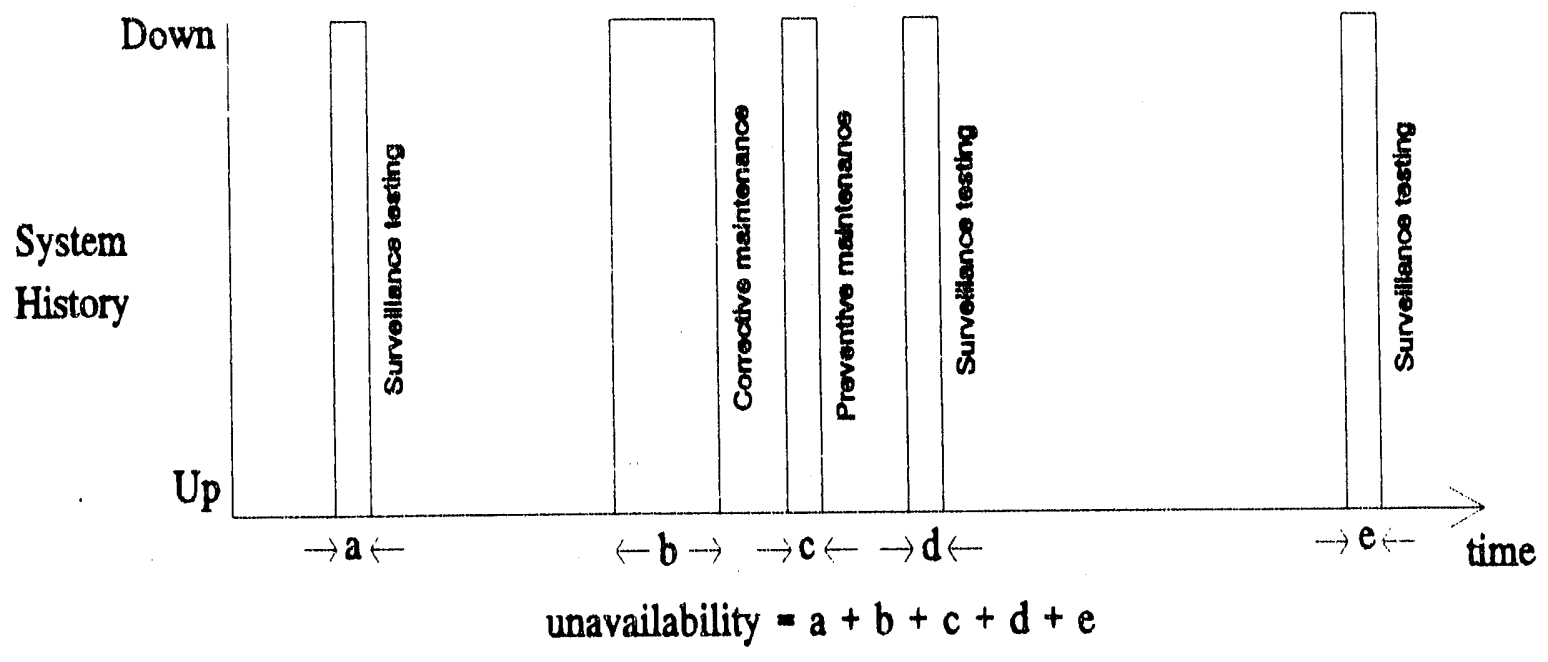

Testing And Maintenance Integrated

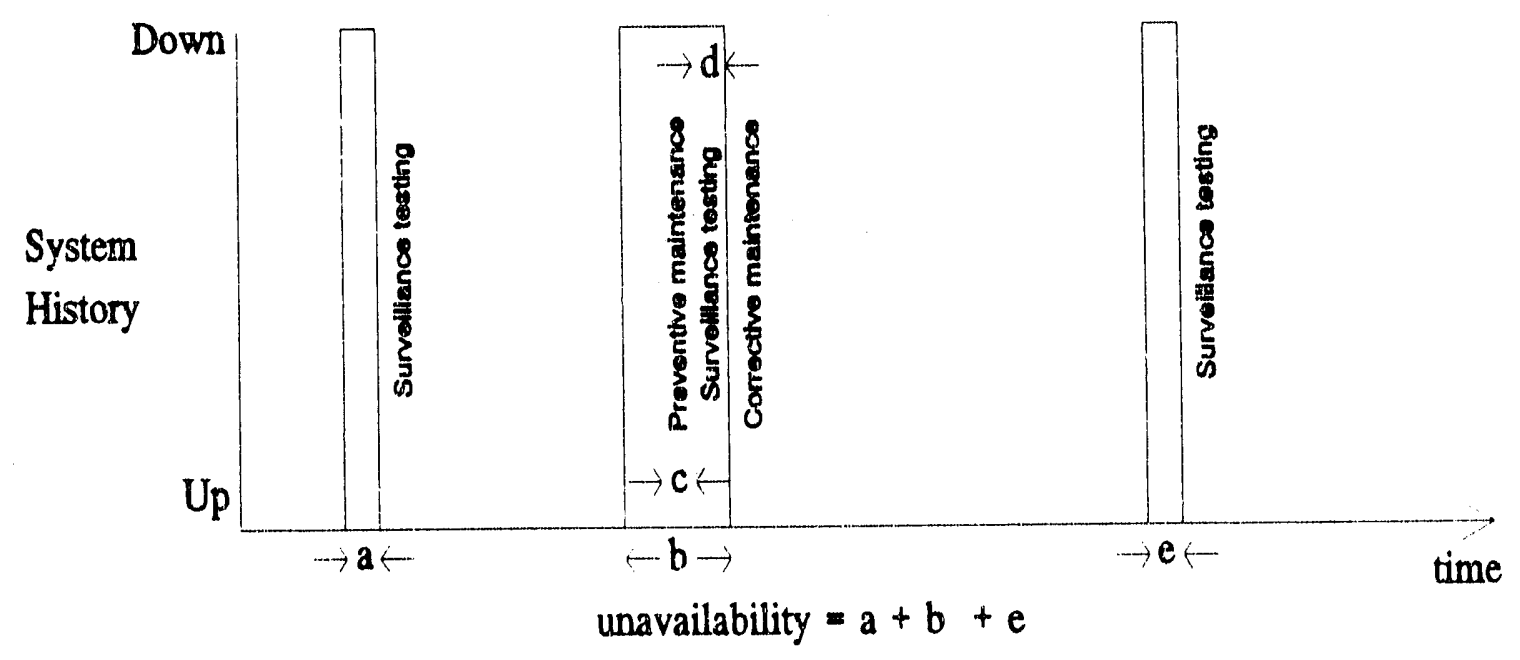

Figure 4. Graphical example of system unavailability with and without integration of testing and maintenance. 
4. The term $\mathrm{q}_{\mathrm{ST}}$ is dependent on the test interval, the time it takes to test the component, and the probability the test will cause an undetected failure. By lengthening the test interval, $\mathrm{q}_{\mathrm{ST}}$ may decrease due to fewer surveillance tests. But, a component may become unavailable due to the surveillance test causing a failure which goes undetected. Lengthening the test interval may increase the chance that piant personnel make a mistake (since the test is performed less frequently). In general though, the amcunt of time the component is unavailable due to testing may be negligible for many tests.

5. Th.e term $\mathrm{q}_{\mathrm{CM}}$ is dependent on the frequency of corrective maintenance, the duration of the maintenance, and the probability that the maintenance will cause an undetected failure. Lengthening the test interval may cause the frequency of corrective maintenance to decrease due to a reduced number of tests. But, the overall frequency of corrective maintenance could increase since it is more likely for random failures to appear between longer testing intervals.

6. The term $\mathrm{q}_{\mathrm{PM}}$ is a function of the frequency of preventive maintenance, the duration of the maintenance, and the probability that the maintenance will cause an undetected failure. The frequency of preventive maintenance and the duration of the maintenance are usually independent of the STI. But, for an integrated test and maintenance program, the test and maintenance intervals would not be independent.

7. Increasing the surveillance testing interval may decrease the number of trips or transients (because of a reduced number of trip opportunities) which should decrease the risk. But, increasing the testing interval may also increase the number of trips or transients (because personnel become less familiar with the component to be tested) which could increase the risk.

The issues raised above will be evaluated and quantified where practical. Several references antress issues of unavailability (see References 2 through 8 ). If a methodology for quantifying the issues a'sove does not exist or is not available, they will be evaluated based upon experience and judgement.

For some issues, two or more competing concerns may exist. For example, on issue number seven, increasing the test interval may decrease the risk due to a reduced number of trip opportunities while at the same time may increase the risk due to a greater chance for a test error causing a trip. These competing issues may negate each other, resulting in no change in risk due to either concern. For those issues where competing concerns negate each other, it may be possible to ignore the issue in the analysis.

The final product from the Task 2 analysis will be guidelines and criteria for the integration of surveillance testing with maintenance. These guidelines are expected to improve NRC test requirements by reducing test frequency and increasing test effectiveness. 


\section{REFERENCES}

1. F. R. Huey, "Operating Practices and Plant Safety: An NRC Perspective," Nuclear News, 34, 15, December 1991, pp. 35-37.

2. E. J. Henley and H. Kumamoto, Reliability Engineering and Risk Assessment, Englewood Cliffs: Prentice-Hall, Inc., 1981.

3. I. S. Kim, et al., Quantitative Evaluation of Surveillance Test Intervals Including Test-Caused Risks, NUREG/CR-5775, 1992.

4. N. J. McCormick, Reliability and Risk Analysis, New York: Academic Press, Inc, 1981.

5. W. E. Vesely, Evaluation of Allowed Outage Times (AOTS) From a Risk and Reliability Standpoint, NUREG/CR-5425, 1989.

6. U. S. Nuclear Regulatory Commission, PRA Procedures Guide, NUREG/CR-2300, January 1983.

7. P. K. Samanta, S. M. Wong, and J. Carbonaro, Evaluation of Risks Associated with AOT and STI Requirements at the ANO-1 Nuclear Power Plant, NUREG/CR-5200, 1988.

8. P. K. Samanta, W. E. Vesely, and I. S. Kim, Study of Operational Risk-Based Configuration Control, NUREG/CR-5641, 1991. 
APPENDIX A: Summary of Region I NRC Survey 
The following 16 questions were presented to NRC personnel at Region I headquarters. Their responses are summarized as follows:

\section{Test Schedules}

1. Discuss whether it is possible to perform maintenance without declaring the associated train inoperable?

Small maintenance items, such as adding oil to a pump, will generally be performed without declaring a train inoperable, provided the train's basic safety function is not impaired. However, if maintenance would change a lineup such that an automatic starting feature or its intended safety function is disabled, then the train should be declared inoperable. It was noted that the interpretation of when to declare an item inoperable varied throughout the industry.

2. If a safety-system train is declared to be inoperable, what testing or assurance activities are performed before the train is declared operable? How do these post-maintenance activities differ from surveillance testing?

Sometimes the surveillance procedure is used to assure that post-maintenance operability is maintained. Whenever possible, maintenance tests are used to satisfy surveillance testing requirements. However, the majority of the time, only a portion of the surveillance test requirement is fulfilled during the maintenance test. Therefore, credit cannot be taken for completing the entire surveillance test. In some cases, the plant would benefit if the partially complete surveillance test were finished.

3. Discuss how surveillance and maintenance schedules are coordinated. Is surveillance routinely performed following maintenance?

The general coisensus was that surveillance and maintenance schedules are not well coordinated at most plants, particularly in the case of corrective maintenance. However, two exceptions were noted where surveillance testing is well coordinated and one in which surveillance testing is performed both before and after maintenance testing.

4. Are surveillance performed only at the specified intervals, or are they performed more often (i.e., following maintenance or inspection activities)?

Under ideal conditions, surveillance tests are not performed unless specifically required. Planned surveillance are normally scheduled to meet the TS requirements for the STI. However, surveillances are generally performed much more frequently than the specified surveillance interval. This can be attributed to a number of reasons. Probably the most 
important aspect is the material condition of the plant. A poor material condition is characterized by an increased number of equipment prcblems. Thus, more corrective maintenance activities will be required, and subsequently more testing will also be required.

Most plants are on a rolling-maintenance schedule.

A recent NRC letter was discussed which says that plants do not have to enter an AOT unless there is a safety benefit. An old NRC letter encouraged maintenance during an AOT.

One reason plants do maintenance during an AOT is so they can use their own people. If they wait until an outage to perform the maintenance, contractors, who are less familiar with plant systems, would have to be used to perform the work resulting in a higher likelihood of errors.

In some cases, the number of surveillance had been increased from every 12 hours to once each eight-hour shift. This increase would prevent overlooking the surveillance, ensure all shift personnel remain familiar with the test, and accommodate the plants shift schedule.

5. Are there any mechanisms in place to automatically schedule surveillance after maintenance activities have been performed?

Most surveillance performed at power are scheduled using computer driven schedules, while surveillance performed during outages or following maintenance are generally scheduled manually. However, the whole surveillance test may not be done or a post-maintenance test other than a surveillance may be used.

6. Have plants discussed the potential usefulness of more flexible STIs? Have any attentsts been made to optimize STIs using PRA or other risk/reliability tools? (Optimizing STIs refers to finding the surveillance interval with the smallest risk associated with it).

A lot of plants have discussed using flexible STIs, but most have not done it yet. Two examples were given of plants that used PRAs to evaluate risks of some maintenance activities on a case by case basis. In general, many plants do not yet have PRAs, and most have not used PRAs to optimize STIs. The plants that have, have done so on a case-by-case basis and often orily to justify continued operation.

Attempts are underway to incorporate risk techniques and improve maintenance and surveillance practices, but risk considerations are rarely used to apply for shorter STIs. 


\section{Risk Impact of Surveillance}

1. To what extent do plants tend to perform surveillance and maintenance in a formal way (written procedures, dedicated groups, formal training) and to what extent do they approach it informally (few or no procedures, assigned as collateral duty, training by word of mouth, etc.)?

Almost all surveillance and maintenance activities are done in a very formal manner using detailed procedures. Trouble-shooting was mentioned as the only possible exception. Often minor maintenance items such as adding oil to equipment are done informally without procedures, but these are usually logged. Major maintenance activities (non-routine) are generally well planned and at some plants include an examination of the risk tradeoffs.

2. In approximately what fraction of preventive maintenance activities could maintenance or test errors potentially disable the component or its associated train? In these instances approximately how much time could elapse before the associated surveillance was performed?

Inoperability due to improper maintenance was generally felt to be low. One Region I plant given as an example had 3 or 4 reworks out of 5,000 outages. However, it was pointed out that the definition of rework may vary among plants and a failed maintenance test may not be defined as rework.

The probability of mistakes being made during the performance of a surveillance or maintenance activity ranged from very low for non-invasive activities to very high for invasive maintenance activities.

3. Discuss the extent to which plants include risk considerations in deciding what maintenance to do during power operation. For mainienance that is undertaken during shutdown conditions, do plants routinely prepare work packages to have on hand in the event of any unplanned outages?

The decision on what maintenance will be done is generally based more on TS requirements than on risk considerations. The typical attitude is: "if you meet the TS, you are OK." Dominant in the decision process is the intention to not exceed an AOT and have to shut down. Therefore, most actions are planned to avoid shutting down. However, in some plants, PRA organizations have been consulted on some isolated cases, but this is not a formal process.

It was indicated that almost all plants routinely have work packages prepared and ready in the event an unplanned outage occurs. 
4. When a train of a risk-significant safety system is inoperable, do plants test or otherwise assure the availability of the other train or alternative success paths beyond what is required in technical specifications?

The answer to this question varied depending on the plant. One comment given was that nobody goes out of their way to find trouble. If a new problem occurs, they will look at the other train. However, sometimes a problem happens frequently, so that it becomes routine instead of being identified as a problem for root cause analysis. In these cases, plants sometimes do not look at the other trains.

Also, when a plant has a problem, sometimes they do not notify sister plants because the plants are in competition with each other.

The consensus seemed to be that if one train of safety related equipment is inoperable, most plants will not check the redundant train for the same failure cause until after they have fixed the first train. Root cause determination was mentioned as the key to many of these problems and that it is not as thorough as it should be at many plants.

In most cases, once the problem was found, a justify continue operation would be generated to continue operating and then the other train would be checked. Single failures are often ignored in these situations.

\section{Feedback}

1. To what extent do utilities track equipment performance and condition and maintenance and test errors? Is this information fed back to engineering for evaluation and problem identification? Is this feedback provided to operations and maintenance to help improve performance?

In general, most plants have a predictive reliability maintenance program. Some have only recently become involved with this program. In many cases, the plants had the tools in place, but they did not use them effectively. Two plants were given as examples of plants that had good programs. These tools were used for troubleshooting rather than for prediction at most plants, with a few notable exceptions.

Utilities are doing more human-performance monitoring, although it is almost non-existent in some plants. Many do it for purposes of productivity improvement. Better root cause analysis is being done, however sometimes they have not gone far enough to identify maintenance human error.

A two-unit site was given as an example in which less than $10 \%$ of the 400 events per year were maintenance error related. 
Feedback to offsite engineering is good if it is requested. That is, if design support is needed, the plant asks for it; if not, they do not ask. The general consensus was that this area is good overall, but is in need of work in some plants.

Feedback is not as good as it should be to other organizations including those doing PRAs, etc. In most cases, this is due to not having a fully developed program. There are some plants that do a very good job, but they are in the minority.

Nuclear plant reliability data system is useful for a plant to compare its problems with other plants.

2. Discuss whether actual equipment failure rates have been factored into lengthening or shortening surveillance test intervals? For example, if the plant is shutdown in mid-cycle for maintenance, are important valves tested, even though technical specifications require only testing during refueling? Similarly, are surveillance intervals lengthened for equipment that never fails?

Plants generally do not factor equipment failure rates into lengthening or shortening of test intervals. Some attempts have been made to lengthen intervals based on PRAs and system performance (not based on observed failures). In situations where they do, this information has mostly been used to justify lengthening the intervals except for instrument calibration intervals which are sometimes shortened.

Sorne diesel testing intervals have been lengthened based on evidence produced demonstrating that the testing was destructive. Some plants were given as examples where more frequent testing has been done, however, this is not the general case.

Most plants now trend test performance levels; not just pass or fail results.

3. To what extent do utilities apply their PRAs to determine risk-significant failures or errors in order to prioritize and plan maintenance and testing?

Many plants do not have PRAs. Of those that do, many do not use them to the extent of prioritizing maintenance work. Often they only use their PRA to justify continued operation.

The perception is that the NRC has not given licensees any incentives to use PRAs to justify TS changes.

The general consensus was that the extent a plant applied a PRA was dependant on the utility more than on whether a PRA was in place. 
4. Discuss examples of plants that have a defined and integrated program to incorporate lessons learned from their PRAs and reliability programs back into their surveillance and maintenance programs?

A number of examples of plants that had various degrees of reliability and PRA programs were discussed. The first had an excellent RCM program with total engineering, quality assurance, and operations involvement. The program was very well defined and integrated. It looked good on paper, but had no practical experience (the plant was never placed in operation).

Another plant given as an example has a "good" reliability centered maintenance program. The PRA is used to evaluate the importance of system and components and then organize maintenance activities accordingly.

The remaining two plants mentioned have PRAs and are in the initial stages of developing reliability centered programs and are slowly improving. One comment made was that RCM seems to work better on (operating) balance-of-plant equipment than on (standby) safety equipment.

It was noted that PRA is not a handy reference document on the desk of every maintenance engineer.

5. Discuss examples of plants where the groups responsible for surveillance, testing, maintenance, data analysis, trending, and modeling (PRA, reliability) are well coordinated and communicate well? Bad examples?

As already indicated, there is a broad spectrum running from poor to good. However, the general consensus was that most plants did poorly in this area. The exceptions to this are the same examples discussed earlier that seemed to consistently do very well. Two plants were discussed that are doing a fairly good job. Two plants were given as examples of not being very far along in this area. One particular plant mentioned, had the best programs on paper, but was slow to apply its programs.

6. Discuss organizational structures or divisions of responsibilities that you have observed to help or hinder surveillance and maintenance?

The following examples were given of things that helped in performing maintenance and surveillance in an effective, well-coordinated manner:

a. Engineering support working at a level that directly supports the Operations Department.

b. Dedicated maintenance planning that is driven by risk priorities

c. System engineers who work with Operations.

d. A Maintenance engineering staff that is associated directly with maintenance. 
e. Work planners responsible to the Maintenance and Operations Departments.

f. Engineering and technical groups with clearly defined responsibilities.

g. Coordination between groups to expedite work packages.

h. Perception by workers that management cares enough about operations to come onsite.

i. Involvement and visibility to operations by engineering and plant and corporate management.

j. Industry-wide experience is circulated to departments within the plant.

The following examples were given as things that hindered the performance of maintenance and surveillance in an effective, well-coordinated manner:

a. Groups onsite reporting to a vice president offsite. For example, work planners responsible to offsite organizations.

b. Work planning driven by schedule.

c. System engineers with little operations experience.

d. Engineering organizations located outside of the fenced area.

e. Multiple engineering and technical organizations without clearly defined responsibilities. 
APPENDIX B: Summary of Region III NRC Survey 
The following 16 questions were presented to NRC personnel at Region III headquarters. Their responses are surnmarized as follows:

\section{Test Schedules}

1. Discuss whether it is possible to perform maintenance without declaring the associated train inoperable?

Small maintenance items, such as changing a filter, will generally be performed without declaring a train inoperable, provided the train's safety function is not impaired. However, if maintenance would change a lineup such that an automatic starting feature or its intended safety function is disabled, then the train should be declared inoperable. It was noted that the interpretation of when to declare an item inoperable varied significantly throughout the industry.

It was also noted that there is wide variation throughout the industry as to what constitutes the disabling of an automatic starting feature. There have been instances where operators have been stationed at valves with inoperable remote actuators so they could be manually operated if required.

2. If a safety-system train is declared to be inoperable, what testing or assurance activities are performed before the train is declared operable? How do these post-maintenance activities differ from surveillance testing?

There is always some form of post-maintenance testing following maintenance (it could be more or less than required by the surveillance program). Actual testing requirements are specified in the maintenance work package. All, part, or none of the surveillance requirement may be specified. Post-maintenance testing does not always recognize the worstcase conditions. And it is often the case that the post-maintenance testing "exercises" a component prior to performing its associated surveillance (i.e., full stroking a valve several times prior to stroke timing it). After being exercised sufficiently, the component will then pass its surveillance, which it might have originally failed if tested prior to being exercised. Trending of failed components varies greatly from plant to plant as does failure reporting. For example, some plants do not consider failure of a post-maintenance test to be a failure reportable to NPRDS.

3. Discuss how surveillance and maintenance schedules are coordinated. Is surveillance routinely performed following maintenance?

In general, surveillance and maintenance schedules are not well coordinated, particularly in the case of corrective maintenance. As discussed previously, all maintenance work packages specify some minimum post-maintenance testing. Depending on the scope of post- 
maintenance testing needed and the time remaining until the end of the surveillance interval, the plant may decide to plan post-maintenance testing that satisfies a surveillance requirement. Work package review is a two step process; the first step verifies that the requirements of the work package were completed; the second step ensures that the maintenance actually performed was adequately inspected.

4. Are surveillance performed only at the specified intervals, or are they performed more often (i.e., following mainternance or inspection activities)?

In theory, surveillances are not performed unless specifically required. Under ideal conditions, planned surveillances are normally scheduled to meet the technical specification requirements for the STI. In actuality though, surveillances are generally performed much more frequently than the specified surveillance interval. This can be attributed to a number of reasons. Probably the most important aspect is the material condition of the plant. A poor material condition is characterized by an increased number of equipment problems. Thus, more corrective maintenance activities will be required, and subsequently more testing will also be required.

In some cases, the number of surveillances are increased to match "shift" requirements. For example, to ensure a surveillance with a 12-hour STI is not over looked, operational requirements may call for it to be performed once per shift (or every eight hours).

Also, there are few "lessons learned" programs that share information on maintenance and surveillance applications between the various utilities.

5. Are there any mechanisms in place to automatically schedule surveillance after maintenance activities have been performed?

The majority of surveillance preformed at power are automatically scheduled using computer driven schedules, while surveillance performed during outages or following maintenance are generally scheduled manually. This is generally done by an individual that is assigned to be the expert and coordinator for these activities at a company. Most plants are attempting to integrate surveillance activities with maintenance activities. Newer plants need to fine tune their programs, but there is a definite learning curve on the best way to integrate scheduling.

6. Have plants discussed the potential usefulness of more flexible STIs? Have any attempts been made to optimize STIs using PRA or other risk/reliability tools? (Optimizing STIs refers to finding the surveillance interval with the smallest risk associated with it).

Flexible STIs have been discussed and some attempts made to modify technical-specification requirements. There is a lack of completed PRAs in Region III. Currently, only one plant in the region has a PRA. Some attempts are underway through the various owners groups to incorporate risk techniques to improve maintenance and surveillance practices. Current 
topics being addressed include: RCM, predictive maintenance, and shutdown risk quantification. Single-plant utilities tend to be less likely to participate in these types of programs. Currently, most RCM programs are being driven by the philosophy "If it is not broken, do not fix it." Those plants that have a predictive maintenance program are just getting them off the ground and presently they are primarily being used as an aid for trouble shooting. A few plants are being innovative in the use of newer predictive maintenance techniques such as: thermography, vibration monitoring, oil analysis, and motor operated valve testing.

Technical specification amendments are sometimes used to pply for lengthening STIs. But risk considerations are rarely if ever used to apply for shorter STIs. In many cases the TS will be used to drive testing requirements in a way that increases the risk. For example, if one of two redundant trains is found to be inoperable, the TS do not require testing the redundant train for operability until some allowed outage time (AOT) has elapsed, during which the inoperable train can be restored. Most utilities and the peeple who regulate them interpret this to mean the redundant train should not be tested until the AOT is nearly over. If there is a common mode failure mechanism causing the failure, then plant risk is greatly increased by delaying testing of the redundant train. One plant was noted whose TS allowed one train of ECCS to be inoperable at the same time the emergency power source for the operable ECCS train was unavailable.

\section{Risk Impact of Surveillance}

1. To what extent do plants tend to perform surveillance and maintenance in a formal way (written procedures, dedicated groups, formal training) and to what extent do they approach it informally (few or no procedures, assigned as collateral duty, training by word of mouth, etc.)?

Surveillance activities are performed in a very formal manner, all plants have detailed procedures. On the other hand, maintenance is generally performed in a less formal manner, particularly at older plants. Older plants tend to rely less on detailed work instructions included in the work packages and more on the experience of longtime employees. Major maintenance activities (non-routine) are generally well planned and at some plants include an examination of the risk tradeoffs.

2. In approximately what fraction of preventive maintenance activities could maintenance or test errors potentially disable the component or its associated train? In these instances approximately how much time could elapse before the associated surveillance was performed?

Estimates of the percentage of preventive maintenance activities that could potentially disable the equipment being maintained ranged from $10 \%$ to $40 \%$. It was felt that in most cases the post-maintenance testing would discover any problem. The probability of mistakes being made during the performance of a surveillance or maintenance activity ranged from high to 
low depending on the complexity of the activity and a number of hard to measure human factors. But, the probability of mistakes being made in properly scheduling surveillance and/or maintenance activities was always judged to be high.

3. Discuss the extent to which plants inciuse risk considerations in deciding what maintenance to do during power operation. For muintenance that is undertaken during shutdown conditions, do plants routinely prepare work packages to have on hand in the event of any unplanned outages?

The Operations Department usually decides what maintenance will be performed. Their decisions are based more on TS requirements than on risk considerations. In the past several plants did not consider the risk of decay heat removal loss. Presently many plants still do not. Some exceptions to these statements are: 1) PWRs mid loop/loss of RHR, 2) BWRs loss of shutdown cooling, and 3 ) loss of electrical grid risk.

A comment was made that some plants had lost RHR in the process of doing ASME "goodfaith" testing. The "good-faith" testing was being conducted without consideration or regard to risk.

It was indicated that almost all plants routinely have work packages prepared and ready in the event an unplanned outage occurs.

4. When a train of a risk-significant safety system is inoperable, do plants test or otherwise assure the availability of the other train or alternative success paths beyond what is required in technical specifications?

The answer to this question is "NO." As stated previously, if one train of safety related equipment is inoperable, most plants will not check the redundant train for the same failure cause until after they have fixed the first train. It was felt that root cause determination is a key to many of these problems and that it is weak at many plants. There is some work being done by owner's groups and some individual utilities are pursuing programs in these areas, but all activities are still in the evaluation phase.

Most of the people we talked with occasionally had problems with safety-related systems that were not part of the TS (systems that would be covered by 10 CFR 50 APP. "A"). The alternate shutdown system resulting from the anticipated-transient-without-scram work was given as an example. The feeling was that it was often difficult to get plants to place these systems back on-line in a timely manner if they were faulted, and that in many cases the systems might be out of service indefinitely. 


\section{Feedback}

1. To what extent do utilities track equipment performance and condition and maintenance and test errors? Is this information fed back to engineering for evaluation and problem identification? Is this feedback provided to operations and maintenance to help improve performance?

Most plants have some sort of predictive maintenance programs. Some have only recently become involved with this program. It was felt that a lot of data were often taken but not much time was spent analyzing the data. In many cases, the plants had the tools in place, but they did not have the knowledge to use them effectively. Three plants were given as examples of plants that, overall, had exceptionally good programs. It was also remarked that a fourth plant had a very good thermal performance monitoring program.

These tools were used for troubleshooting rather than for prediction at most plants, with a few notable exceptions. The tracking of human errors is almost non-existent, although some plants do it for purposes of productivity improvement. This information, if it exists, is almost never fed back to other organizations including those that are doing PRA, RCM, etc. In general, the feedback of information is not good. In some cases this is due to not having a fully developed program, and in other cases it is due to inexperience. There are some plants that do a very good job, but they are in the minority.

2. Discuss whether actual equipment failure rates have been factored into lengthening or shortening surveillance test intervals? For example, if the plant is shutdown in mid-cycle for maintenance, are important valves tested, even though technical specifications require only testing during refueling? Similarly, are surveillance intervals lengthened for equipment that never fails?

In general, the answer to this question is that plants do not factor equipment failure rates into lengthening or shortening the test intervals. In those situations where they do, they have used information mostly to justify lengthening the intervals, except for instrument calibration intervals which are sometimes shortened. It was pointed out that few plants have completed their PRAs and, therefore, they did not have any analytical tools to make a risk/benefit tradeoff. And even though most of the plants have, to some extent, been involved in RCM work, many have not done much with it and some have given up on it entirely. In some cases, data has been used for some special projects, but this is not done on a routine bases. There are also some cases where work in this area has been by state and federal regulatory agencies or by code requirements. 
3. To what extent do utilities apply their PRAs to determine risk-significant failures or errors in order to prioritize and plan maintenance and testing?

In Region III, only one plant had a completed PRA, but most plants looked at errors and failures using knowledgeable people to qualitatively evaluate and prioritize maintenance and testing. Many plants have evaluated the use of RCM but there was not enough experience yet in this area to see if it was going to be used. In some cases, plants had stopped any work they were doing in RCM. In general, maintenance priorities are driven by needs for power generation (within TS limits).

4. Discuss examples of plants that have a defined and integrated program to incorporate lessons learned from their PRAs and reliability programs back into their surveillance and maintenance programs?

No one could cite any good examples. Most plants have a low-key, or in many cases nonexistent. program in this area. Funding and interest is low and responsibilities are collateral. An example was given where a person with responsibility for one system might be experiencing numerous failures with a particular item, and another person may be experiencing the same kind of failures on a separate system and neither of them would be aware of the other's situation. The general appraisal was that coordination between groups and areas of responsibility left much to be desired.

5. Discuss examples of plants where the groups responsible for surveillance, testing, maintenance, data analysis, trending, and modeling (PRA, reliability) are well coordinated and communicate well? Bad examples?

As already indicated, there is a broad spectrum running from poor to good. However, the general consensus was that most plants did poorly in this area. There were some exceptions to this (three plants seemed to consistently do very well). Two other plants were listed as doing a fairly good job. Two plants were given as examples of doing a fairly poor job. The examples were not restricted to just Region III. One particular company was cited as having the best programs on paper but that they were slow to implement their programs. Another plant was given as an example of a plant that did a good job of work planning.

6. Discuss organizational structures or divisions of respopsibilities that you have observed 10 help or hinder surveillance and maintenance?

The following examples were given of things that helped in performing maintenance and surveillance in an effective, well-coordinated manner:

a. Engineering support working at a level that directly supports the Operations Department

b. Work planning that is driven by risk/priorities 
c. System engineers that work with Operations

d. Radiation protection personnel available for maintenance support

e. Work planners responsible to the Maintenance and Operations Departments.

f. Multiple engineering and technical groups with clearly defined responsibilities.

The following examples were given as things that hindered the performance of maintenance and surveillance in an effective, well-coordinated manner:
a. Engineering support at only the corporate level
b. Work planning driven by schedule
c. System engineers with little operations experience
d. Lack of health physics support on the back shift
e. Work planners responsible to offsite organizations
f. Multiple engineering and technical organizations without clearly defined responsibilities.


APPENDIX C: Summary Of Former Nuclear Utility Engineer Survey 
The following 16 questions were presented to INEL engineers with utility experience. Their responses are summarized as follows:

\section{Test Schedules}

1. Discuss whether it is possible to perform maintenance without declaring the associated train inoperable?

As long as a component has not been disabled due to the maintenance being performed, it can be repaired without declaring the component inoperable. For example, adding oil to a pump or testing a system (if it can re-align on an automatic signal) may not require declaring the system inoperable. But, most maintenance (on the order of $95 \%$ ) will require the component to be declared inoperable.

2. If a safery-system train is declared to be inoperable, what testing or assurance activities are performed before the train is declared operable? How do these post-maintenance activities differ from surveillance testing?

In general, the portion of the surveillance test that tests for operability is performed as a minimum. Occasionally, additional testing is prescribed. Post-maintenance assurance activities do not differ substantially from surveillance activities and, in many cases, are the same.

3. Discuss how surveillance and maintenance schedules are coordinated. Is surveillance routinely performed following maintenance?

Initially, some plants may not have coordinated surveillance testing and maintenance very well. As plant personnel gained experience, testing and maintenance became better coordinated. In general, planned maintenance was coordinated with surveillance testing. However, unplanned maintenance may or may not be followed by a scheduled surveillance. Operability was assured by performing the operability surveillance.

4. Are surveillance performed only at the specified intervals, or are they performed more often (i.e., following maintenance or inspection activities)?

If maintenance is required between the surveillance interval, additional post-maintenance testing may be performed. Even though surveillance testing may be performed more often than at specified intervals, credit probably will not be taken for the additional testing.

5. Are there any mechanisms in place to automatically schedule surveillance after maintenance activities have been performed?

Some plants have computerized update systems. But, for plants that do not have automatic systems, personnel will ensure that the proper surveillance testing are performed. 
6. Have plants discussed the potential usefulness of more flexible STIs? Have any attempts been made to optimize STIs using PRA or other risk/reliability tools? (Optimizing ST7s refers to finding the surveillance interval with the smallest risk associated with it).

In general, no. Some optimization of surveillance has been considered. The optimization considered reducing the number of tests for high reliability systems or components that may be more likely to fail with increased testing.

\section{Risk Impact of Surveillance}

1. To what extent do plants tend to perform surveillance and maintenance in a formal way (written procedures, dedicated groups, formal training) and to what extent do they approach it informally (few or no procedures, assigned as collateral duty, training by word of mouth, e(c.)?

Most surveillance and maintenance, and the personnel performing the operations, are performed in a very formal manner. Training and written instructions are formally controlled. Exceptions to the formal maintenance is sometimes made for specialized testing (e.g., steam generator tube lancing) or for non-critical equipment. But in general, surveillance arid maintenance are based on controlled, written procedures and are formally tracked.

2. In approximately what fraction of preventive maintenance activities could maintenance or test errors potentially disable the component or its associated train? In these instances approximately how much time could elapse before the associated surveillance was performed?

This depends on the type of maintenance and can vary greatly. The fraction can be around $5.90 \%$. The test required at the end of the maintenance would probably detect the error, but could go undetected until the next preventive maintenance or until the equipment is operated.

3. Discuss the extent to which plants include risk considerations in deciding what maintenance to do during power operation. For maintenance that is undertaken during shutdown conditions, do plants routinely prepare work packages to have on hand in the evert of any unplanned outages?

Generally, risk considerations are not taken into account during maintenance, but can vary greatly. For maintenance, the TS will be considered, and may limit the degree or frequency of the maintenance that is performed. Work packages are usually prepared in advance (as far as possible) and kept up-to-date in case of unplanned outages. As soon as the plant enters the unplanned outage, processing normally begins on the work packages. 
4. When a train of a risk-significant safety system is inoperable, do plants test or otherwise assure the availability of the other train or alternative success paths beyond what is required in technical specifications?

Generally NO. Unless formally required by the TS no additional tests are performed. What is normally done is that the records for the last surveillance test are checked to see if the other train was operable and when the next test is required. If the next test is due shortly, the train may be tested early. Also, if the failure mode may be common to both trains, the other train may be tested, but usually only after the first train is fixed.

\section{Feedback}

1. To what extent do utilities track equipment performance and condition and maintenance and test errors? Is this information fed back to engineering for evaluation and problem identification? Is this feedback provided to operations and maintenance to heip improve performance?

Some plants track and analyze testing and maintenance errors and disseminate the lessons learned to both maintenance and operations. Other plants only perform this detailed feedback for reoccurring errors or failures or for problem items (reactor coolant pump seals, main circulation pump seals, etc.). Operations generally are not involved unless there is a design modification that alters the operations procedures.

2. Discuss whether actual equipment failure rates have been factored into lengthening or shortening surveillance test intervals? For example, if the plant is shutdown in mid-cycle for maintenance, are important valves tested, even though technical specifications require only testing during refueling? Similarly, are surveillance intervals lengthened for equipment shat never fails?

In general, test intervals can be shortened, but usually are never lengthened. Shortening of test intervals will occur if required, such as failures requiring more frequent tests. Lengthening test intervals is usually against TS. If history of component showed that testing was excessive, the test interval may be increased if the TS is changed.

3. To what extent do utilities apply their PRAs to determine risk-significant failures or errors in order to prioritize and plan maintenance and testing?

None or not known. The TS generally state the limiting conditions of operation. As such, the PRA is not usually used. 
4. Discuss examples of plants that have a defined and integrated program to incorporate lessons learned from their PRAs and reliability programs back into their surveillance and maintenance programs?

None known. Some plants use PRA assumptions to evaluate procedure, design, or TS changes. There is generally no formal process to incorporate reliability data into testing or maintenance programs.

5. Discuss examples of plants where the groups responsible for surveillance, testing, maintenance, data analysis, trending, and modeling (PRA, reliability) are well coordinated and communicate well? Bad examples?

One plant discussed could be considered as average. Some groups in this plant (Engineering, Regulatory Compliance) had sections that were dedicated to coordination and reporting surveillance testing and maintenance. The Operations and Maintenance groups generally worked independent of engineering guidance, but did have coordination with the Work Planning group and Operations. Another plant was considered to be pretty good. Surveillances have been coordinated with the TS section to ensure that all required tests were performed. A weak area was in the evaluation of operational data. Also, the PRA group was not involved in plant testing (except for interaction with the Reliability group).

6. Discuss organizational structures or divisions of responsibilities that you have observed to help or hinder surveillance and maintenance?

A good example would be having Operations personnel reviewing work scope or testing requirements. This saved time because these people had a good idea of system interrelationships, capability of equipment, and operability requirements. Another positive example is having one person or department responsible to ensure that surveillance testing is completed. A weak area is the lack of tracking inoperable equipment to make sure that maintenance is performed in the required time. 
7
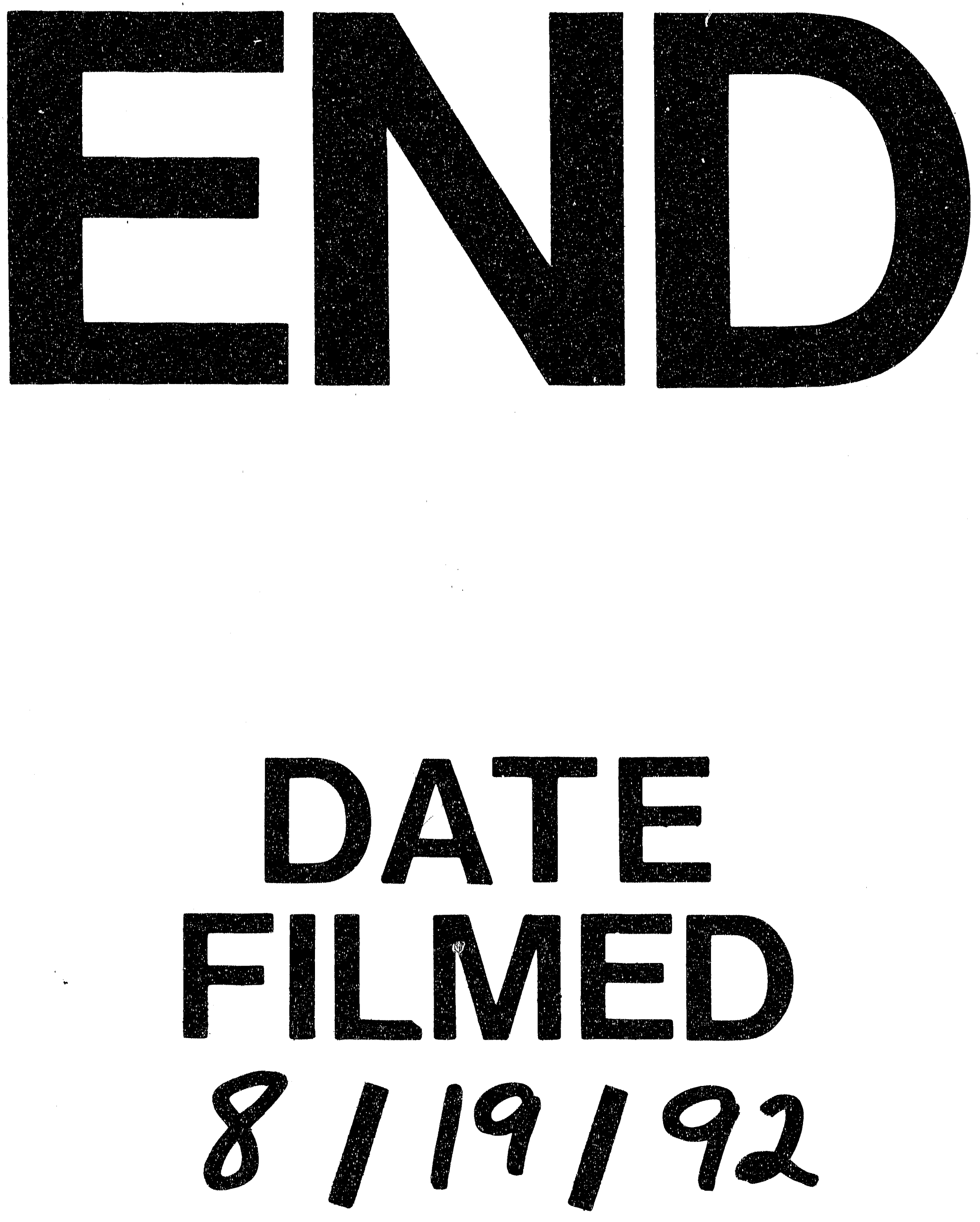
